\title{
Combination of susceptibility gene and traditional risk factors might enhance the performance of coronary heart disease screening strategy
}

\author{
Shiyan Nian ${ }^{1, *}$, Lei Feng, ${ }^{2, *}$ Yang Zhao ${ }^{3}$, Feng $\mathrm{Luo}^{3}$, Shu Zhang ${ }^{3}$, Dan $\mathrm{Li}^{2}$, Wenbo \\ $\mathrm{Xu}^{2}$, Xingfeng Zhang ${ }^{2}$, Dan $\mathrm{Ye}^{2}$ and Xuejing $\mathrm{Bai}^{3}$ \\ ${ }^{1}$ Intensive Care Unit, People's Hospital of Yuxi City, Yuxi, Yunnan, P.R. China \\ 2 Department of Laboratory, People's Hospital of Yuxi City, Yuxi, Yunnan, P.R. China \\ ${ }^{3}$ Department of Laboratory, The Sixth Affiliated Hospital of Kunming Medical University, Yuxi, Yunnan, P.R. China \\ * These authors have contributed equally to this study \\ Correspondence to: Shiyan Nian, email: nsyenglish@126.com \\ Lei Feng, email: fngj2004@163.com \\ Keywords: coronary heart disease; serum biochemical indices; susceptibility gene; screening strategy; performance \\ Received: January 23, $2017 \quad$ Accepted: March 19, $2017 \quad$ Published: March 29, 2017
}

Copyright: Nian et al. This is an open-access article distributed under the terms of the Creative Commons Attribution License 3.0 (CC BY 3.0), which permits unrestricted use, distribution, and reproduction in any medium, provided the original author and source are credited.

\section{ABSTRACT}

Coronary heart disease (CHD) associated risk factors and susceptibility genes were studied in parallel for decades, however, the combination of the classic CHD risk factors and genetic risk factors has been rarely studied. Previously; we reported that a single nucleotide polymorphism (SNP) in the stromal cell-derived factor 1 (SDF-1) gene was associated with CHD risk; in addition, we also established a CHD screening strategy using traditional CHD risk factors as independent variables. To explore how to combine genetic factors and traditional risk factors in CHD screening strategy, the CHD probabilities were tested in $\mathbf{2 1 8}$ males and 121 females according to their stromal cell-derived factor 1 (SDF-1) genotypes using CHD screening equations we reported previously. The genotypes had not altered the distribution characteristics of age, high-density lipoprotein cholesterol (HDL-C), triglyceride (TG), lipoprotein(a) (LP(a)), homocysteine (HCY) and total bilirubin (TBil) in males and age, HDL-C, HCY and Y-glutamyl transpeptidase (GGT) in females among genotypes. However, the mean CHD probability of subjects with G/G genotype was significantly higher than that of subjects with A/A genotype $(0.51 \pm 0.35$ vs. $0.31 \pm 0.31, P=0.035)$. The mean CHD probability of subjects with $G$ homozygous and $G$ heterozygote was $0.48 \pm$ 0.34 which displayed a difference trend to that of subjects with A homozygous $(0.31$ $\pm 0.31, P=0.059)$. Our data suggested that genetic risk factors might be used as a classification standard to improve current CHD screening strategies.

\section{INTRODUCTION}

Coronary heart disease (CHD) remains a persistent public health burden worldwide [1,2]. The Global Burden of Disease report showed that ischemic cardiomyopathy was the leading cause of death, accounting for as much $12.2 \%$ of all deaths worldwide, with 7.2 million deaths in 2004 [1, 2]. CHD has been the focus of global medical research for almost a century [3]. Epidemiological studies have identified that age, sex, family history and ethnicity are classic un-modifiable risk factors and hypertension, dyslipidemia and diabetes are classic modifiable risk factors [4-10].

Single nucleotide polymorphisms (SNPs) are also widely studied in individual's genetic predisposition for CHD [11]. Genome-wide association studies (GWAS) have identified more than 100 gene variants that are associated with CHD as reported in the National Human Genome Research Institute catalog [12]. These studies advance our understanding on the pathogenesis of CHD, 
and greatly improved the prevention, diagnosis as well as treatment on CHD. Recently, our group had reported that a SNP (rs1801157) in the stromal cell-derived factor 1 (SDF-1) gene (located at q11.21 on chromosome 10) is associated with CHD in our Chinese [13]. Multivariable logistic regression analysis showed that the onset of CHD in population with $\mathrm{G} / \mathrm{G}$ genotype is 2.31 times higher than that in population with A/A genotype [13].

Meanwhile, a number of serum biochemical markers, which reflect dynamic physiological and pathophysiological processes within the body, had been found to be associated with CHD [7-10]. Our previous study showed that integrated serum biochemical indices may be used to screen for suspected CHD in our Chinese [14-16]. The raw or logarithm transformed age, highdensity lipoprotein cholesterol (HDL-C), triglyceride (TG), lipoprotein(a) (LP(a)), homocysteine (HCY) and total bilirubin (TBil) could be used to screen CHD risk in a equation with distinct coefficient in males [14]. The raw or logarithm transformed age, HDL-C, HCY and $\gamma$-glutamyl transpeptidase (GGT) could be used to screen CHD risk in another equation with distinct coefficient in females [14].

Although the predicting strategy has evolved remarkably and more and more CHD associated SNPs were reported, the combination of the classic CHD risk factors and genetic risk factors has been rarely studied. The issues regarding how to combine the classic risk factors with genetic risk factors and whether genetic risk factors could further improve the performance of the predicting strategies using classic CHD risk factor are worthy of attention. In this report, our screening equations for suspected CHD using integrated serum biochemical indices were tested in 218 males and 121 females according to their SDF-1 genotypes retrospectively.

\section{RESULTS}

\section{Distribution characteristics of gender specific traditional CHD risk factors, CHD probability and SDF-1 genotypes in CHD patients and controls}

Our previous study showed that CHD probability for males and females could be calculated using following equations $[14,16]$ :

$$
\text { Probability }\left(\mathrm{CHD}_{\text {male }} \quad \text { final }\right)=\quad 1 /\{1+\exp -(-
$$$$
\text { 6.846+0.102age-3.316HDL-C-0.677lnTG+ }
$$$$
0.481 \ln L \mathrm{p}(\mathrm{a})+2.195 \ln \mathrm{HCY}-0.725 \ln \mathrm{TBIL})\} \text {; }
$$$$
\text { Probability }\left(\mathrm{CHD}_{\text {female }} \quad \text { final }\right)=\quad 1 /\{1+\exp -(-
$$

15.356+0.180age-3.105HDL-C+2.938

$\ln \mathrm{HCY}+0.904 \ln \gamma-\mathrm{GT})\}$.

Table 1 showed the distribution characteristics of above gender specific traditional CHD risk factors. Of males; age, HDL-C, Lp(a) and HCY were significantly higher in CHD patients than these in controls; conversely, TBil was significantly lower in CHD patients than that in controls; TG level displayed a difference trend between CHD patients and controls; the CHD probabilities of CHD patients and controls calculated using above variables were $0.87 \pm 0.17$ and $0.30 \pm 0.24$ respectively. Of females; age, HDL-C, HCY and GGT were significantly higher in CHD patients than these in controls; the CHD probabilities of CHD patients and controls calculated using above variables were $0.87 \pm 0.19$ and $0.21 \pm 0.26$ respectively.

Of the SDF-1 genotypes; the percentage of $\mathrm{G} / \mathrm{G}$ genotype in male CHD patients $(62.1 \%)$ was significantly higher than that in male controls $(48.7 \%)$; no other difference was found between CHD patients and controls (Table 1).

\section{Genotypes have not changed the distribution tendency of classic CHD risk factors in males and females}

To learn whether SDF-1 genotype will alter the distribution tendency of CHD risk factors in males and females, the study subjects were pooled together and regrouped by their SDF-1 genotypes. As showed in Table 2, of males, no significant difference was observed between $\mathrm{G} / \mathrm{G}, \mathrm{G} / \mathrm{A}$ and $\mathrm{A} / \mathrm{A}$ genotypes regarding age, HDL-C as well as logarithm transformed TG, Lp(a), HCY and TBil. Similarly, as showed in Table 3, of females, no significant difference was observed between $\mathrm{G} / \mathrm{G}, \mathrm{G} / \mathrm{A}$ and $\mathrm{A} / \mathrm{A}$ genotypes regarding age, HDL-C as well as logarithm transformed HCY and GGT.

\section{Male subjects with $G$ allele displayed higher probability of CHD}

Although above analysis showed that SDF-1 genotypes have not changed the distribution tendency of CHD risk factors in males and females, we are still not sure whether the genotypes will alter the CHD probability calculated by the following equation:

Probability $\left(\mathrm{CHD}_{\text {male }}\right.$ final $)=\quad 1 /\{1+$ exp(-6.846+0.102age-3.316HDL-C-0.677lnTG+

$0.481 \ln L \mathrm{p}(\mathrm{a})+2.195 \ln \mathrm{HCY}-0.725 \ln \mathrm{TBIL})\}$.

To clarify this issue, the pooled male subjects were regrouped by their SDF-1 genotypes, the mean CHD probabilities of each genotype group were calculated. As showed in table 4; although the mean probabilities of each genotype group were low; the mean CHD probability of $\mathrm{G} / \mathrm{G}$ genotype group was significantly higher than that of A/A genotype group $(0.51 \pm 0.35$ vs. $0.31 \pm 0.31, P$ $=0.035)$. The mean CHD probability of $\mathrm{G}$ homozygous and $\mathrm{G}$ heterozygote was $0.48 \pm 0.34$ which displayed a difference trend to that of A homozygous $(0.31 \pm 0.31, P$ $=0.059$ ). 
Table 1: Distribution characteristics of gender specific CHD risk factors, CHD probability and SDF-1 genotypes in CHD patients and controls.

\begin{tabular}{|c|c|c|c|}
\hline & CHD & Control & $\boldsymbol{P}$ \\
\hline \multicolumn{4}{|c|}{ Male $(n=218) ; n$ for CHD, $66 ; n$ for Control, 152} \\
\hline Age (yr) & $62.5 \pm 10.4$ & $35.0 \pm 9.2$ & $<0.001$ \\
\hline HDL-C $(\mathrm{mmol} / \mathrm{L})$ & $1.14 \pm 0.26$ & $1.03 \pm 0.28$ & 0.008 \\
\hline TG $(\mathrm{mmol} / \mathrm{L})$ & $1.52(1.19,2.20)$ & $1.81(1.04,3.05)$ & 0.092 \\
\hline $\mathrm{Lp}(\mathrm{a})(\mathrm{mg} / \mathrm{L})$ & $194.00(80.00,338.50)$ & $79.00(37.50,177.00)$ & $<0.001$ \\
\hline HCY (umol/L) & $22.00(14.25,26.00)$ & $14.00(11.00,17.00)$ & $<0.001$ \\
\hline TBil (umol/L) & $10.10(7.53,12.05)$ & $13.10(10.10,18.05)$ & $<0.001$ \\
\hline CHD Probability & $0.87 \pm 0.17$ & $0.30 \pm 0.24$ & $<0.001$ \\
\hline $\mathrm{G} / \mathrm{G}, \mathrm{n}(\%)$ & $41(62.1)$ & $74(48.7)$ & 0.046 \\
\hline $\mathrm{G} / \mathrm{A}, \mathrm{n}(\%)$ & $23(34.8)$ & $66(43.4)$ & 0.151 \\
\hline $\mathrm{A} / \mathrm{A}, \mathrm{n}(\%)$ & $2(3.1)$ & $12(7.9)$ & 0.147 \\
\hline \multicolumn{4}{|c|}{ Female $(n=121) ; n$ for CHD, 20; $n$ for Control, 101} \\
\hline Age (yr) & $62.0 \pm 9.1$ & $32.2 \pm 8.5$ & $<0.001$ \\
\hline HDL-C $(\mathrm{mmol} / \mathrm{L})$ & $1.27 \pm 0.27$ & $1.05 \pm 0.25$ & 0.003 \\
\hline $\mathrm{HCY}(\mathrm{umol} / \mathrm{L})$ & $18.50(13.50,24.75)$ & $14.00(11.00,16.00)$ & 0.001 \\
\hline GGT (IU/L) & $31.00(19.25,91.75)$ & $21.00(14.00,34.50)$ & 0.012 \\
\hline CHD Probability & $0.87 \pm 0.19$ & $0.21 \pm 0.26$ & \\
\hline $\mathrm{G} / \mathrm{G}, \mathrm{n}(\%)$ & $9(45.0)$ & $46(45.5)$ & 0.581 \\
\hline $\mathrm{G} / \mathrm{A}, \mathrm{n}(\%)$ & $9(45.0)$ & $45(44.6)$ & 0.580 \\
\hline $\mathrm{A} / \mathrm{A}, \mathrm{n}(\%)$ & $2(10.0)$ & $10(9.9)$ & 0.627 \\
\hline
\end{tabular}

Normally distributed data were presented as means \pm standard deviation (SD), skewed data were presented as the median (interquartile range). Differences between groups were examined by using t test and Fisher exact probability test according to the data distribution tendency. Abbreviations: SDF-1, stromal cell-derived factor 1; TG, triglyceride; HDL-C, high density lipoprotein cholesterol; Lp(a), Lipoprotein(a); HCY, homocysteine; TBil, total bilirubin; GGT, gamma-glutamyl transpeptidase.

\section{G allele did not increase the probability of CHD in female subjects}

To learn whether $\mathrm{G}$ allele will alter the CHD probability in females, the female subjects were also regrouped by SDF-1 genotypes, the CHD probability calculated by the following equation:

Probability $\left(\mathrm{CHD}_{\text {female }} \quad\right.$ final $)=\quad 1 /\{1+\exp -(-$ 15.356+0.180age-3.105HDL-C $+2.938 \ln \mathrm{HCY}+0.904 \ln \gamma-$ GT) .

As showed in Table 5, the mean CHD probabilities of $\mathrm{G} / \mathrm{G}$ and $\mathrm{A} / \mathrm{A}$ genotype groups were $0.33 \pm 0.36$ and $0.38 \pm 0.43$, respectively, no significant difference was observed between two genotype groups.

The mean CHD probability of $\mathrm{G}$ homozygous and $\mathrm{G}$ heterozygote was $0.31 \pm 0.35$ which displayed no significant difference to that of A homozygous $(0.38 \pm$ $0.43)$.

\section{DISCUSSION}

Classic risk factors of $\mathrm{CHD}$, such as age, sex, hypertension, dyslipidemia, and diabetes, have studied nearly for a century [3-10]. Now, we can try to predict CHD risk using several well-known prognostic models including equations derived from the Framingham Heart Study [17], the Women's Health Study [18], the Prospective Cardiovascular Münster study [19] and the Systematic Coronary Risk Evaluation project [20]. Recently, the atherosclerotic cardiovascular disease risk in China project has also developed effective tools with good performance for ten-year atherosclerotic cardiovascular disease risk prediction among Chinese population [21]. Yet, these CHD risk estimation strategies still confined to traditional risk factors and its practical application is still need to be improved. The directions for improvement include inclusion of new risk factors and combination of genetic factors. This report has the following merits: firstly, our models including markers of liver function and 
Table 2: Distribution tendency of the male-specific risk factors by genotypes

\begin{tabular}{|c|c|c|c|c|}
\hline & $\mathbf{G} / \mathbf{G}$ & G/A & $\mathbf{A} / \mathbf{A}$ & \multirow{2}{*}{$P$} \\
\hline & $(n=115)$ & $(n=89)$ & $(n=14)$ & \\
\hline Age (yr) & $44.6 \pm 16.5$ & $42.3 \pm 14.2$ & $35.4 \pm 18.0$ & 0.100 \\
\hline $\begin{array}{l}\text { HDL-C } \\
(\mathrm{mmol} / \mathrm{L})\end{array}$ & $1.05 \pm 0.26$ & $1.08 \pm 0.30$ & $1.06 \pm 0.25$ & 0.794 \\
\hline $\operatorname{lnTG}$ & $0.57 \pm 0.68$ & $0.59 \pm 0.64$ & $0.51 \pm 0.66$ & 0.922 \\
\hline $\operatorname{lnLp}(\mathrm{a})$ & $4.64 \pm 0.97$ & $4.61 \pm 1.16$ & $4.57 \pm 0.98$ & 0.962 \\
\hline $\ln \mathrm{HCY}$ & $2.75 \pm 0.43$ & $2.66 \pm 0.44$ & $2.73 \pm 0.46$ & 0.319 \\
\hline lnTBil & $2.50 \pm 0.42$ & $2.47 \pm 0.45$ & $2.42 \pm 0.52$ & 0.766 \\
\hline
\end{tabular}

Data were presented as means $\pm \mathrm{SD}$. Abbreviations: TG, triglyceride; HDL-C, high density lipoprotein cholesterol; Lp(a), Lipoprotein(a); HCY, homocysteine; TBil, total bilirubin; ln, logarithm transformed. Differences among groups were examined by using Kruskal-Wallis $\mathrm{H}$ test, one-way ANOVA, $\chi 2$ tests according to the data distribution tendency.

Table 3: Distribution tendency of the female-specific risk factors by genotypes

\begin{tabular}{|l|c|c|c|c|}
\hline \multirow{2}{*}{} & $\mathbf{G} / \mathbf{G}$ & $\mathbf{G} / \mathbf{A}$ & $\mathbf{A} / \mathbf{A}$ & \multirow{2}{*}{$\boldsymbol{P}$} \\
\cline { 2 - 5 } & $(\boldsymbol{n}=\mathbf{5 5})$ & $(\boldsymbol{n}=\mathbf{5 4})$ & $(\boldsymbol{n}=\mathbf{1 2})$ & \\
\hline Age $(\mathrm{yr})$ & $37.7 \pm 14.3$ & $36.2 \pm 13.6$ & $38.8 \pm 16.6$ & 0.797 \\
\hline HDL-C $(\mathrm{mmol} / \mathrm{L})$ & $1.12 \pm 0.26$ & $1.07 \pm 0.29$ & $0.99 \pm 0.16$ & 0.254 \\
\hline $\operatorname{lnHCY}$ & $2.66 \pm 0.36$ & $2.59 \pm 0.28$ & $2.72 \pm 0.33$ & 0.309 \\
\hline $\ln$ lnGT & $3.24 \pm 0.74$ & $3.13 \pm 0.65$ & $3.04 \pm 0.63$ & 0.548 \\
\hline
\end{tabular}

Data were presented as means \pm SD. Abbreviations: HDL-C, high density lipoprotein cholesterol; HCY, homocysteine; GGT, gamma-glutamyl transpeptidase; ln, logarithm transformed.

Table 4: Male subjects with G allele displayed higher probability of CHD

\begin{tabular}{|l|c|c|c|}
\hline & $n$ & Mean Probability & P \\
\hline G homozygous vs. A homozygous & $0.51 \pm 0.35$ & \multirow{2}{*}{0.035} \\
\hline G/G & 115 & $0.31 \pm 0.31$ & \multirow{2}{*}{0.059} \\
\hline A/A & 14 & $0.48 \pm 0.34$ & \\
\hline G homozygous and G heterozygote vs. A homozygous & $0.31 \pm 0.31$ & \\
\hline G/G + G/A & 204 & & \\
\hline A/A & 14 & &
\end{tabular}

HCY; secondly, we have tried the combination of SDF1 genotypes with the biochemical risk factors. The ideal value of our equations to predict CHD is 1.00; the closer to 1.00 the higher the risk, the closer to 0.00 the lower the risk. In clinical practice, we do not know whether a visitor we met is a CHD patients or not, so we pooled the CHD patients and controls together to compare the mean CHD probabilities of each SDF-1 genotype. In males, the $\mathrm{G} / \mathrm{G}$ genotype subjects are at significantly higher CHD probability than that of A/A genotype subjects. G homozygous and $\mathrm{G}$ heterozygote subjects also showed a higher tendency of CHD probability when compared with A homozygous subjects. The above phenomenon was not observed in female subjects, this might be explained by sex difference. In conclusion, our data provided an idea for the combination of genetic factors and traditional risk factors in the future.
SDF-1, i.e. C-X-C motif chemokine 12 (CXCL12), is a chemokine that encoded by the CXCL12 gene [22, 23]. SDF-1 is induced by proinflammatory stimuli such as tumour necrosis factor, lipopolysaccharide or interleukin-1 and may activate T-lymphocytes. SDF-1 activates $\mathrm{C}-\mathrm{X}-\mathrm{C}$ chemokine receptor type 4 to induce a rapid and transient rise in the level of chemotaxis and intracellular calcium ions [22-25]. SDF-1 may also bind to atypical chemokine receptor 3 , which activates the $\beta$-arrestin pathway and acts as a scavenger receptor for SDF-1 [22-25]. Thus, SDF1 plays an important role in host inflammatory responses [22-25]. SNP at rs1801157 in the 3'-untranslated region [13]. A allele is regarded as a target of cis-acting factors, has been shown to up-regulate the expression of CXCL12 [26]. Our previous study found that $\mathrm{G} / \mathrm{G}$ genotype of SDF-1 gene was associated with higher risk of CHD [13]. In this report, subjects with SDF-1 G/G genotype have 
Table 5: G allele did not increase the probability of $\mathrm{CHD}$ in female subjects

\begin{tabular}{|l|c|c|c|}
\hline \multicolumn{1}{|c|}{$n$} & Mean Probability & \multicolumn{1}{|c|}{$\boldsymbol{P}$} \\
\hline G homozygous vs. A homozygous & 55 & $0.33 \pm 0.36$ & \multirow{2}{*}{0.701} \\
\hline G/G & 12 & $0.38 \pm 0.43$ & \\
\hline A/A & 109 & $0.31 \pm 0.35$ & \multirow{2}{*}{0.524} \\
\hline G homozygous and G heterozygote vs. A homozygous & $0.38 \pm 0.43$ & \\
\hline G/G + G/A & 12 &
\end{tabular}

elevated slightly in the CHD probability, this might also be explained by that the main role of SDF-1 is to modulate inflammatory responses but not metabolic physiology.

Although our models used to screen CHD patients were derived from large samples with rigorous statistical analysis, the main disadvantage of our study is the mismatching of age between cases and controls. In addition, our models were developed from a crosssectional study, the results need further validation using a prospective study.

\section{MATERIALS AND METHODS}

\section{Ethics issues}

The Review Board of the Sixth Affiliated Hospital of Kunming Medical University (People's Hospital of Yuxi City, Yuxi, China) approved the protocol of this study (approval number: YNYXH2010-0012; 1 May 2010). Written informed consent was obtained according to the guidance of the Chinese National Ethics Regulation Committee. Participants were simultaneously informed of their right to repeal consent by themselves or their kin, caretakers, or guardians.

\section{Subjects}

As we reported previously, 339 local Chinese (218 males and 121 females) were recruited consecutively at the People's Hospital of Yuxi City between September 2010 and December 2012 to assess the association between SDF-1 gene polymorphisms and presence of CHD. Of the 339 subjects, 86 and 253 were CHD patients and healthy controls, respectively. Patients were diagnosed with CHD according to American Heart Association guidelines [27]. All patients were confirmed by the obstruction of at least 1 large epicardial coronary artery by atheromatous plaque using coronary angiography [13]. Patients who met the exclusion criteria will be exclude from this study: alcohol abuse, diabetes, a history of smoking, chronic lung disease, xanthelasma, and evidence of noncoronary atherosclerotic disease. The 253 healthy controls did not have a history of chronic disease, autoimmune disease, or cardiovascular disease. A questionnaire was self-completed by all participants; the questionnaire includs ethnicity, sex, age, family history, medical history, smoking status and alcohol abuse.

\section{Polymorphism genotyping}

As we reported previously [13], SNP at rs1801157 of SDF-1 gene was identified using the MassARRAY ${ }^{\circledR}$ system (Sequenom, San Diego, CA, USA). The MassARRAY ${ }^{\circledR}$ system is based on single base primer extension technology. MassARRAY® technology uses matrix-assisted laser desorption ionization time-of-flight mass spectrometry to measure the mass of the extension product(s) directly and to correlate the detected mass with a specific genotype. A 293-bp SDF-1 fragment (covering rs1801157) was PCR-amplified using the primers F (5'-CAGTCAACCTGGGCAAAGCC-3') and R (5'-CCTGAGAGTCCTTTTGCGGG-3') (GenBank accession number: L36033). The extension primer sequence was 5'-GCCCTCCCAGAAGAGGCAGACC-3'. For details on the protocol, please refer to "SNP Genotyping Using the Sequenom MassARRAY® iPLEX Platform (http://www.sequenom.com/)".

\section{Clinical data collection}

A fasting blood sample was collected from each participant in the morning of the day on which he or she visited our hospital. Serum lipid profiles, including triglycerides (TG), total cholesterol (TC), highdensity lipoprotein-cholesterol (HDL-C), low-density lipoproteincholesterol (LDL-C), and apolipoprotein (apo)A, apoB, apoE, and lipoprotein (Lp) (a); indicators of kidney function, including UA; indicators of liver function, including gamma-glutamyl transpeptidase (GGT), total bilirubin (TBil), indirect bilirubin (IBil), and direct bilirubin (DBil); and HCY levels, were measured in our hospital's laboratory using routine procedures.

Waking blood pressure was measured in the morning using a mercury sphygmomanometer. Hypertension was defined as a systolic pressure $\geq 140 \mathrm{mmHg}$ or diastolic 
pressure $\geq 90 \mathrm{mmHg}$ according to the American Society of Hypertension guidelines [28].

\section{Statistical analysis}

All analyses were performed using SPSS for Windows software (ver. 18.0; SPSS Inc., Chicago, IL, USA) and the significance level (alpha) was set at 0.05 . Differences between groups were explored using the Kruskal-Wallis H test or one-way ANOVA, depending on the distribution tendency of the data. According to our previous report and doctoral thesis, the CHD probability for male and female was calculated using following equations $[14,16]$ :

Probability $\left(\mathrm{CHD}_{\text {male }} \quad\right.$ final $)=\quad 1 /$ $\{1+\exp -(-6.846+0.102$ age-3.316HDL-C$0.677 \operatorname{lnTG}+0.481 \operatorname{lnLp}(\mathrm{a})+2.195 \ln \mathrm{HCY}-0.725 \ln \mathrm{TBIL})\}$; Probability $\left(\mathrm{CHD}_{\text {female }} \quad\right.$ final $)=\quad 1 /\{1+\exp -(-$ 15.356+0.180age-3.105HDL-C+2.938 $\ln \mathrm{HCY}+0.904 \ln \gamma-$ GT)\} .

\section{CONFLICTS OF INTEREST}

The authors declare no conflicts of interest.

\section{GRANT SUPPORT}

This research was supported by the Regional Fund Project (Serial number: 81460326) of the National Natural Science Foundation of China; Yunnan Provincial Science and Technology Department of Basic Research on the Application of Self-Financing Projects (Serial number: 2013FZ257); Joint Special Funds (Code: 2013FZ283) from the Yunnan Province Science and Technology Department and Department of Applied Basic Research of Kunming Medical University; the Scientific Research Fund of Yunnan Provincial Education Department (Serial number: 2011C083) and the Training Special Funds of High Level Health and Family Planning Technical Personnel in Yunnan Province (Serial number: D-201644). The findings had no role in study design; in the collection, analysis, and interpretation of data; in writing the report; and in the decision to submit the article for publication.

\section{REFERENCES}

1. Moran AE, Forouzanfar MH, Roth GA, Mensah GA, Ezzati M, Flaxman A, Murray CJ, Naghavi M. The global burden of ischemic heart disease in 1990 and 2010: the Global Burden of Disease 2010 study. Circulation. 2014; 129:1493-501.

2. World Health Organization. Global Burden of Disease 2004. http://www.who.int/healthinfo/global_burden disease/2004_report_update/en/

3. Howell JD. Coronary heart disease and heart attacks, 1912
2010. Med Hist. 2011; 55:307-12.

4. Lloyd-Jones DM. Cardiovascular risk prediction: basic concepts, current status, and future directions. Circulation. 2010; 121:1768-77.

5. Payne RA. Cardiovascular risk. Br J Clin Pharmacol. 2012; 74:396-410.

6. Anderson KM, Wilson PW, Odell PM, Kannel WB. An updated coronary risk profile. A statement for health professionals. Circulation. 1991; 83:356-62.

7. Lerner DJ, Kannel WB. Patterns of coronary heart disease morbidity and mortality in the sexes: a 26-year follow-up of the Framingham population. Am Heart J. 1986; 111:38390.

8. Chow CK, Islam S, Bautista L, Rumboldt Z, Yusufali A, Xie C, Anand SS, Engert JC, Rangarajan S, Yusuf S. Parental history and myocardial infarction risk across the world: the INTERHEART Study. J Am Coll Cardiol. 2011; 57:619-27.

9. Forouhi NG, Sattar N. CVD risk factors and ethnicity-a homogeneous relationship? Atheroscler Suppl. 2006; 7:1119.

10. Lewington S, Clarke R, Qizilbash N, Peto R, Collins R, and Prospective Studies Collaboration. Age-specific relevance of usual blood pressure to vascular mortality: a meta-analysis of individual data for one million adults in 61 prospective studies. Lancet. 2002; 360:1903-13.

11. Rankinen T, Sarzynski MA, Ghosh S, Bouchard C. Are there genetic paths common to obesity, cardiovascular disease outcomes, and cardiovascular risk factors? Circ Res. 2015; 116:909-22.

12. National Human Genome Research Institute Catalog. Available online: http://www.genome.gov/gwasstudies (accessed on 12 April 2016).

13. Feng L, Nian SY, Hao YL, Xu WB, Ye D, Zhang XF, Li D, Zheng L. A single nucleotide polymorphism in the stromal cell-derived factor 1 gene is associated with coronary heart disease in Chinese patients. Int J Mol Sci. 2014; 15:11054 63.

14. Feng L, Zhang C, Nian S, Hao Y, Xu W, Zhang X, Zhang J, Li L. Screening for suspected coronary heart disease in patients, using integrated serum biochemical indices. J Epidemiol Community Health. 2016; 70:195-201.

15. Feng L, Nian S, Zhang S, Xu W, Zhang X, Ye D, Zheng L. The associations between serum biomarkers and stenosis of the coronary arteries. Oncotarget. 2016; 7:39231-40. doi: 10.18632/oncotarget.9645.

16. Feng L. Clinical biochemical indexes based coronary heart disease predicting model and exploratory study on combination with genetic susceptibility. Doctoral Thesis. DOI: CNKI:CDMD:1.1016.261084

17. D'Agostino RB Sr, Vasan RS, Pencina MJ, Wolf PA, Cobain M, Massaro JM, Kannel WB. General cardiovascular risk profile for use in primary care: the Framingham Heart Study. Circulation. 2008; 117:743-53. 
18. Ridker PM, Buring JE, Rifai N, Cook NR. Development and validation of improved algorithms for the assessment of global cardiovascular risk in women: the Reynolds Risk Score. JAMA. 2007; 297:611-19.

19. Assmann G, Cullen P, Schulte H. Simple scoring scheme for calculating the risk of acute coronary events based on the 10-year follow-up of the prospective cardiovascular Münster (PROCAM) study. Circulation. 2002; 105:310-15.

20. Conroy RM, Pyörälä K, Fitzgerald AP, Sans S, Menotti A, De Backer G, De Bacquer D, Ducimetière P, Jousilahti P, Keil U, Njølstad I, Oganov RG, Thomsen T, et al, and SCORE project group. Estimation of ten-year risk of fatal cardiovascular disease in Europe: the SCORE project. Eur Heart J. 2003; 24:987-1003.

21. Yang X, Li J, Hu D, Chen J, Li Y, Huang J, Liu X, Liu F, Cao J, Shen C, Yu L, Lu F, Wu X, et al. Predicting the 10 -Year Risks of Atherosclerotic Cardiovascular Disease in Chinese Population: The China-PAR Project (Prediction for ASCVD Risk in China). Circulation. 2016; 134:1430-40.

22. Bleul CC, Fuhlbrigge RC, Casasnovas JM, Aiuti A, Springer TA. A highly efficacious lymphocyte chemoattractant, stromal cell-derived factor 1 (SDF-1). J Exp Med. 1996; 184:1101-09.

23. Ara $\mathrm{T}$, Nakamura $\mathrm{Y}$, Egawa $\mathrm{T}$, Sugiyama $\mathrm{T}$, Abe $\mathrm{K}$, Kishimoto T, Matsui Y, Nagasawa T. Impaired colonization of the gonads by primordial germ cells in mice lacking a chemokine, stromal cell-derived factor-1 (SDF-1). Proc Natl Acad Sci USA. 2003; 100:5319-23.
24. Askari AT, Unzek S, Popovic ZB, Goldman CK, Forudi F, Kiedrowski M, Rovner A, Ellis SG, Thomas JD, DiCorleto PE, Topol EJ, Penn MS. Effect of stromal-cell-derived factor 1 on stem-cell homing and tissue regeneration in ischaemic cardiomyopathy. Lancet. 2003; 362:697-703.

25. Ma Q, Jones D, Borghesani PR, Segal RA, Nagasawa T, Kishimoto T, Bronson RT, Springer TA. Impaired B-lymphopoiesis, myelopoiesis, and derailed cerebellar neuron migration in CXCR4- and SDF-1-deficient mice. Proc Natl Acad Sci USA. 1998; 95:9448-53.

26. Hirata H, Hinoda Y, Kikuno N, Kawamoto K, Dahiya AV, Suehiro Y, Tanaka Y, Dahiya R. CXCL12 G801A polymorphism is a risk factor for sporadic prostate cancer susceptibility. Clin Cancer Res. 2007; 13:5056-62.

27. Smith SC Jr, Benjamin EJ, Bonow RO, Braun LT, Creager MA, Franklin BA, Gibbons RJ, Grundy SM, Hiratzka LF, Jones DW, Lloyd-Jones DM, Minissian M, Mosca L, et al, and World Heart Federation and the Preventive Cardiovascular Nurses Association. AHA/ACCF Secondary Prevention and Risk Reduction Therapy for Patients with Coronary and other Atherosclerotic Vascular Disease: 2011 update: a guideline from the American Heart Association and American College of Cardiology Foundation. Circulation. 2011; 124:2458-73.

28. Perloff D, Grim C, Flack J, Frohlich ED, Hill M, McDonald M, Morgenstern BZ. Human blood pressure determination by sphygmomanometry. Circulation. 1993; 88:2460-70. 